\title{
Amyloid formation in human IAPP transgenic mouse islets and pancreas, and human pancreas, is not associated with endoplasmic reticulum stress
}

\author{
R. L. Hull • S. Zraika • J. Udayasankar • \\ K. Aston-Mourney • S. L. Subramanian • S. E. Kahn
}

Received: 31 July 2008 /Accepted: 19 February 2009/Published online: 8 April 2009

(C) US Government 2009

\begin{abstract}
Aims/hypothesis Supraphysiological levels of the amyloidogenic peptide human islet amyloid polypeptide have been associated with beta cell endoplasmic reticulum (ER) stress. However, in human type 2 diabetes, levels of human IAPP are equivalent or decreased relative to matched controls. Thus, we sought to investigate whether ER stress is induced during amyloidogenesis at physiological levels of human IAPP.

Methods Islets from human IAPP transgenic mice that develop amyloid, and non-transgenic mice that do not, were cultured for up to 7 days in $11.1,16.7$ and $33.3 \mathrm{mmol} / 1$ glucose. Pancreases from human IAPP transgenic and nontransgenic mice and humans with or without type 2 diabetes were also evaluated. Amyloid formation was determined histologically. ER stress was determined in islets by quantifying mRNA levels of Bip, Atf4 and Chop (also known as Ddit3) and alternate splicing of $X b p 1$ mRNA, or in pancreases by immunostaining for immunoglobulin heavy chain-binding protein (BIP), C/EBP homologous protein (CHOP) and X-box binding protein 1 (XBP1).

Results Amyloid formation in human IAPP transgenic islets was associated with reduced beta cell area in a

R. L. Hull $(\bowtie) \cdot$ S. Zraika · J. Udayasankar · K. Aston-Mourney •

S. L. Subramanian $\cdot$ S. E. Kahn

Division of Metabolism, Endocrinology and Nutrition,

VA Puget Sound Health Care System (151),

1660 S. Columbian Way,

Seattle, WA 98108, USA

e-mail: rhull@u.washington.edu

R. L. Hull · S. Zraika $\cdot$ J. Udayasankar $\cdot$ K. Aston-Mourney •

S. L. Subramanian $\cdot$ S. E. Kahn

Division of Metabolism, Endocrinology and Nutrition,

Department of Medicine, University of Washington,

Seattle, WA, USA
\end{abstract}

glucose- and time-dependent manner. However, amyloid formation was not associated with significant increases in expression of ER stress markers under any culture condition. Thapsigargin treatment, a positive control, did result in significant ER stress. Amyloid formation in vivo in pancreas samples from human IAPP transgenic mice or humans was not associated with upregulation of ER stress markers.

Conclusions/interpretation Our data suggest that ER stress is not an obligatory pathway mediating the toxic effects of amyloid formation at physiological levels of human IAPP.

Keywords Beta cell death - Endoplasmic reticulum .

ER stress · IAPP. Islet amyloid

\author{
Abbreviations \\ ATF4 Activating transcription factor 4 \\ ATF6 Activating transcription factor 6 \\ BIP Immunoglobulin heavy chain-binding protein \\ CHOP C/EBP homologous protein \\ ER Endoplasmic reticulum \\ IAPP Islet amyloid polypeptide \\ IRE1 Inositol requiring ER to nucleus signalling kinase 1 \\ PERK PKR-like ER kinase \\ XBP1 X-box binding protein 1
}

\section{Introduction}

Deposition of islet amyloid, formed from the beta cell peptide islet amyloid polypeptide (IAPP), occurs in approximately $90 \%$ of individuals with type 2 diabetes and is associated with reduced beta cell volume [1, 2]. Human IAPP is amyloidogenic, and in vitro studies show that early aggregates or oligomers of human IAPP are 
cytotoxic and induce apoptosis [3-7], while rodent IAPP is not amyloidogenic [8]. Thus, human IAPP and/or the process of islet amyloid formation are likely to contribute to the decreased beta cell mass observed in type 2 diabetes by inducing beta cell apoptosis [9]. We and others have developed transgenic mice with beta cell expression of human IAPP as models of islet amyloid formation (reviewed in [10]). Cultured islets from these transgenic mice develop amyloid in a time- and glucose-dependent manner [11] and this amyloid is associated with decreased beta cell area, reduced islet cell viability [11] and increased beta cell apoptosis [12].

Aggregation of human IAPP involves a conformational change to predominantly beta sheet structure $[8,13]$. All amyloidogenic peptides undergo this conformational change, leading to the hypothesis that amyloid formation is associated with protein misfolding [14]. Normal trafficking of secretory proteins such as insulin and IAPP through the endoplasmic reticulum (ER) is monitored to prevent misfolding or aggregation [15]. Under physiological conditions, accumulation of proteins in the ER triggers the adaptive unfolded protein response [16, 17]. This response includes three major pathways: signalling through inositol requiring ER to nucleus signalling kinase 1 (IRE1), proteolysis and activation of activating transcription factor 6 (ATF6) and signalling through PKR-like ER kinase (PERK) [16]. Activation of all three pathways increases production of ER chaperone proteins (including Ig heavy chain-binding protein [BIP]), increases degradation of misfolded proteins and attenuates new protein synthesis $[16,17]$. Under adverse conditions, such as increased cytokines $[18,19]$ or non-esterified fatty acid exposure $[19,20]$, these mechanisms are no longer capable of protecting the cell, and this normally adaptive unfolded protein response becomes an ER stress response. Under conditions of ER stress, expression of pro-apoptotic genes including that encoding $\mathrm{C} / \mathrm{EBP}$ homologous protein (CHOP), also known as growth arrest and DNA damage 153 (GADD153), is increased and the cell undergoes apoptosis [21].

Markers of ER stress have been shown to be increased, to variable degrees, in post-mortem pancreas samples [20, $22,23]$ and isolated islets from individuals with type 2 diabetes [23], where amyloid deposition is known to occur. In other amyloid-related diseases, ER-stress-mediated cell death has been shown to occur in response to aggregation of the amyloidogenic peptides amyloid-beta [24] and the prion protein $\operatorname{PrP}^{\mathrm{Sc}}$ [25]. Recently, two groups have demonstrated ER stress following treatment of islets with exogenous human IAPP [26] or in islets with high expression rates of human IAPP [22, 27]. In the latter case, ER stress occurred with overexpression of amyloidogenic human IAPP but not with overexpression of non- amyloidogenic rodent Iapp [27]. However, these studies cannot exclude the possibility that the marked increase of amyloidogenic human IAPP, rather than aggregation of human IAPP per se, was responsible for the observed ER stress response. In the present study, we investigated whether induction of ER stress occurs during amyloid formation in the presence of physiological levels of human IAPP, and whether ER stress may thereby mediate some of the cytotoxic effects of human IAPP aggregation.

\section{Methods}

Islet isolation and culture Islets were isolated from 10 week old male and female hemizygous human IAPP transgenic mice or non-transgenic littermate controls on an F1 C57BL/6 $\times$ DBA/2 background as we have done previously [11, 28]. Wild-type breeders were from Jackson Laboratories (Bar Harbor, ME, USA). Studies were approved by the Institutional Animal Care and Use Committee of the VA Puget Sound Health Care System. Islets were handpicked and cultured overnight in RPMI-1640 containing 10\% fetal bovine serum, $100 \mathrm{U} / \mathrm{ml}$ penicillin, $100 \mu \mathrm{g} / \mathrm{ml}$ streptomycin and $11.1 \mathrm{mmol} / 1$ glucose. Islets were then cultured for 7 days in medium containing 5.5, 11.1, 16.7 or $33.3 \mathrm{mmol} / 1$ glucose ( $n=4-6$ per condition) or for up to 7 days in $16.7 \mathrm{mmol} / 1$ glucose $(n=3-4$ per condition). To provide a positive control for the induction of ER stress, a subset of human IAPP transgenic or non-transgenic islets were cultured in the presence of $16.7 \mathrm{mmol} / \mathrm{l}$ glucose $+0.3 \mu \mathrm{mol} / \mathrm{l}$ thapsigargin for the final $4 \mathrm{~h}$ of the culture period.

Use of 5.5 or $11.1 \mathrm{mmol} / \mathrm{l}$ glucose as the control culture condition Initially, $5.5 \mathrm{mmol} / 1$ glucose was used as the control culture condition. However, culture of human IAPP transgenic (data not shown) or non-transgenic islets for 7 days in $5.5 \mathrm{mmol} / 1$ glucose was associated with a $5.1 \pm 0.8$ fold increase in mRNA levels for the pro-apoptotic gene Chop (also known as Ddit3) $(p=0.001, \mathrm{n}=5)$, relative to islets cultured in $11.1 \mathrm{mmol} / \mathrm{l}$ glucose. No change in Bip or Atf4 mRNA levels $(1.3 \pm 0.1$ and $1.4 \pm 0.1$ fold increase over $11.1 \mathrm{mmol} / 1$ glucose, respectively) were seen under the same culture conditions, and no alternate splicing of Xbpl mRNA was observed (data not shown), suggesting that culture of mouse islets for 7 days in $5.5 \mathrm{mmol} / 1$ glucose is associated with a stress response that is distinct from the ER stress response. Thus, $5.5 \mathrm{mmol} / \mathrm{l}$ glucose was determined to be an inappropriate control condition and therefore all data are compared with $11.1 \mathrm{mmol} / \mathrm{l}$ glucose as the control condition.

Histological measurement of amyloid deposition and beta cell area in cultured islets Islets were fixed for $30 \mathrm{~min}$ at 
$4^{\circ} \mathrm{C}$ in $4 \%$ (wt/vol.) phosphate-buffered paraformaldehyde and embedded in agar and then in paraffin as we have done previously [28]. Sections of $10 \mu \mathrm{m}$ thickness were cut, and sections at $100 \mu \mathrm{m}$ intervals throughout the islet pellet were stained with thioflavin $\mathrm{S}$ to visualise amyloid deposits and insulin antibody to visualise beta cells [28]. Islets were visualised in the thioflavin $\mathrm{S}$ channel where the islet outline is clearly visible and the cross-sectional area of each islet was computed using Image Pro Plus (Media Cybernetics, Bethesda, MD, USA). Thioflavin S and insulin-positive areas within each islet cross section were then determined.

An average of 28 islets per experimental condition were analysed. Investigators were blinded to the genotype and experimental treatment of each sample. From these data, islet amyloid prevalence (percentage of islets containing thioflavin S-positive staining) and islet amyloid severity ( $\Sigma$ thioflavin $\mathrm{S}$ area $/ \Sigma$ islet area $\times 100 \%$ ), islet area and beta cell area (expressed as $\mu \mathrm{m}^{2}$ or $\%$ islet area) were determined.

\section{$R N A$ isolation and quantitative real-time PCR Total islet RNA} was isolated from 25 islets per condition (High Pure RNA isolation kit, Roche Applied Science, Indianapolis, IN, USA) and reverse transcribed (High Capacity cDNA Archive kit, Applied Biosystems, Foster City, CA, USA). Levels of mRNA expression for Bip, Chop and Atf4 were measured in triplicate by real-time quantitative PCR using TaqMan assays on demand (Applied Biosystems), with 18S ribosomal RNA levels serving as the endogenous control, as we have described previously [29]. mRNA levels were expressed relative to an experimental control (either nontransgenic islets cultured for 7 days in $11.1 \mathrm{mmol} / 1$ glucose or non-transgenic islets harvested on day 1 , depending on the experimental paradigm) using the $\Delta \Delta C_{\mathrm{t}}$ method.

Alternate splicing of $X b p 1$ mRNA was determined from islet cDNA by PCR of a fragment of $X b p 1$ cDNA (using oligonucleotide primers TCCTTCTGGGTAGACCTCT GGGAG and AAACAGAGTAGCAGCGCAGACTGC). The normal $X b p 1$ PCR product is $473 \mathrm{bp}$, while the spliced form is $447 \mathrm{bp}$. The PCR product was subjected to restriction digestion with $P s t I$, which cleaves only the normal unspliced form of $X b p 1$ cDNA (generating fragments of 290 and $183 \mathrm{bp}$ ). Reaction products were separated by agarose electrophoresis.

Immunohistochemical assessment of ER stress in vivo Pancreases were obtained from male human IAPP transgenic mice or and age-matched non-transgenic mice $(n=3$ per genotype) following 1 year of high-fat feeding (diet containing 45\% energy from fat, D12290 from Research Diets, New Brunswick, NJ, USA) that we have previously shown to be associated with islet amyloid formation, loss of beta cell area and beta cell secretory dysfunction [30]. Human pancreases were obtained from autopsy cases $(n=3)$ from the University of Washington or VA Puget Sound Health Care System Pathology Departments. The studies using human autopsy samples were approved by the Human Subjects Review Committee at the University of Washington.

Pancreas samples were fixed in 4\% (wt/vol.) phosphatebuffered paraformaldehyde (for mouse pancreas) or in neutral-buffered formalin (for human pancreas), embedded in paraffin and $5 \mu \mathrm{m}$ sections were cut. Sections were subjected to antigen retrieval consisting of 20-40 $\mathrm{min}$ incubations in Tris-EDTA buffer, $\mathrm{pH} 8.0$, in a container submerged in a boiling water bath. Non-specific binding was blocked by incubation in phosphate-buffered saline containing 1\% (wt/vol.) BSA and 2\% (vol./vol.) normal goat serum. Primary antisera were as follows. BIP antisera were 610979 (lot 59027; BD Biosciences, San Jose, CA, USA), diluted 1:500 (mouse pancreas) or 1:100 (human pancreas) and SPA-826 (lot 06050826; Stressgen Bioreagents, Ann Arbor, MI, USA) diluted 1:100. CHOP antisera were ab11419 (lot 559553; AbCam, Cambridge, MA, USA) diluted 1:100 and sc-575 (lots D0103, E0207 and G1708; Santa Cruz Biotechnology, Santa Cruz, CA, USA) diluted 1:100. Lot D0103 of the CHOP antibody sc-575 was kindly provided by R. Laybutt (Garvan Institute of Medical Research, Sydney, Australia). XBP1 antibody was sc-7160 (lot G2607) from Santa Cruz Biotechnology, diluted 1:50. All antisera were reported to cross-react with both mouse and human ER stress markers. Sections were incubated overnight at $4^{\circ} \mathrm{C}$ in primary antibody, then incubated for $1 \mathrm{~h}$ at room temperature with the appropriate biotinylated secondary antibody, diluted 1:200 (Jackson ImmunoResearch, West Grove, PA, USA) followed by avidin-biotin-horseradish peroxidase conjugate (Vectastain ABC Elite, Vector Laboratories, Burlingame, CA, USA). Antibody binding was visualised with 3,3'-diaminobenzidine and sections were counterstained with haemotoxylin. Thioflavin $\mathrm{S}$ and insulin staining were performed as described above.

Data analysis Data are expressed as mean \pm SEM. Data were compared by analysis of variance with post hoc analysis or by non-parametric test (Kruskal-Wallis or Mann-Whitney $U$ ) if the data were not normally distributed. A $p$ value $\leq 0.05$ was considered statistically significant.

\section{Results}

Islet amyloid formation in cultured islets As we have shown previously, culture of human IAPP transgenic islets for 7 days in 16.7 or $33.3 \mathrm{mmol} / 1$ glucose is associated with a dose-dependent increase in islet amyloid formation, while 
Table 1 Morphometric analyses of human IAPP transgenic and non-transgenic islets cultured for 7 days in $11.1,16.7$ or $33.3 \mathrm{mmol} / \mathrm{g} \mathrm{glucose}$

\begin{tabular}{|c|c|c|c|c|c|c|}
\hline \multirow{2}{*}{$\begin{array}{l}\text { Genotype } \\
\text { Glucose (mmol/1) }\end{array}$} & \multicolumn{3}{|c|}{ Human $I A P P$ transgenic } & \multicolumn{3}{|c|}{ Non-transgenic } \\
\hline & $11.1(n=4)$ & $16.7(n=4)$ & $33.3(n=4)$ & $11.1(n=4)$ & $16.7(n=4)$ & $33.3(n=4)$ \\
\hline Amyloid prevalence $(\%)$ & $30 \pm 7^{\mathrm{a}}$ & $46 \pm 16^{\mathrm{a}}$ & $65 \pm 6^{\mathrm{a}, \mathrm{b}}$ & 0 & 0 & 0 \\
\hline Amyloid severity (\%) & $0.3 \pm 0.04^{\mathrm{a}}$ & $2.1 \pm 1.3^{\mathrm{a}}$ & $3.3 \pm 0.5^{\mathrm{a}, \mathrm{b}}$ & 0 & 0 & 0 \\
\hline Islet cross sectional area $\left(\mu \mathrm{m}^{2}\right)$ & $11,505 \pm 905$ & $12,074 \pm 1,631$ & $12,355 \pm 935$ & $13,282 \pm 857$ & $12,726 \pm 651$ & $11,574 \pm 1,486$ \\
\hline Beta cell area $\left(\mu \mathrm{m}^{2}\right)$ & $7,055 \pm 779$ & $6,001 \pm 847$ & $5,434 \pm 651$ & $9,188 \pm 494$ & $7,620 \pm 168$ & $6,653 \pm 815$ \\
\hline Beta cell area/islet area $(\%)$ & $61.1 \pm 3.7^{\mathrm{a}}$ & $49.5 \pm 1.9^{\mathrm{a}, \mathrm{b}}$ & $43.3 \pm 3.8^{\mathrm{c}, \mathrm{b}}$ & $69.3 \pm 1.0$ & $61.6 \pm 3.2$ & $57.7 \pm 1.5^{\mathrm{d}}$ \\
\hline
\end{tabular}

Values are mean \pm SEM

${ }^{\mathrm{a}} p<0.05$ vs non-transgenic cultured at the same glucose concentration

${ }^{\mathrm{b}} p<0.05$ vs transgenic, $11.1 \mathrm{mmol} / \mathrm{l}$ glucose

${ }^{\mathrm{c}} p<0.005$ vs non-transgenic cultured at the same glucose concentration

${ }^{\mathrm{d}} p<0.05$ vs non-transgenic, $11.1 \mathrm{mmol} / 1$ glucose

very little amyloid deposition is present in islets cultured for the same period in $11.1 \mathrm{mmol} / \mathrm{l}$ glucose (Table 1). Similarly, islet amyloid severity increases over time when human IAPP transgenic islets are cultured in $16.7 \mathrm{mmol} / \mathrm{l}$ glucose (Table 2). Amyloid formation occurring in response to either increased glucose or duration of culture at $16.7 \mathrm{mmol} / \mathrm{l}$ glucose was associated with reduced beta cell area (Tables 1 and 2).

Effect of increasing glucose on ER stress markers in cultured islets Culture of either human IAPP transgenic (not shown) or non-transgenic islets for 7 days in $16.7 \mathrm{mmol} / \mathrm{l}$ glucose with the addition of $0.3 \mu \mathrm{mol} / 1$ thapsigargin for the last $4 \mathrm{~h}$ was associated with significant increases in Bip, Atf4 and Chop mRNA levels (Fig. 1) and with a marked increase in alternative splicing of $X b p 1$ mRNA (Fig. 2).

In contrast, 7 days of culture in 16.7 or $33.3 \mathrm{mmol} / \mathrm{l}$ glucose, conditions that are associated with increased amyloid deposition in human IAPP transgenic islets (Table 1), was not associated with any changes in Bip, Atf4 or Chop mRNA levels (Fig. 1), or with alternate splicing of Xbpl mRNA (Fig. 2).

Effect of time on ER stress markers in cultured islets In order to determine whether changes in ER stress markers occur only during the early stages of islet amyloid formation, samples were taken from human IAPP trans- genic and non-transgenic islets on days 1 to 7 of culture at $16.7 \mathrm{mmol} / \mathrm{l}$ glucose. On day 1 there was very little visible amyloid formation while at subsequent time points there was a progressive increase in amyloid formation over time (Table 2). Culture of human IAPP and non-transgenic islets over 7 days at $16.7 \mathrm{mmol} / 1$ glucose was not associated with a time-dependent increase in Bip, Atf4 or Chop mRNA levels (Fig. 3). No changes in $X b p 1$ mRNA splicing were observed over the 7 day culture period in either human $I A P P$ transgenic or non-transgenic islets (Fig. 4). In fact, Atf4 and Chop mRNA levels decreased from day 1 to day 2 in both human IAPP transgenic and non-transgenic islets, in keeping with recovery from islet isolation being associated with decreased expression of ER stress markers.

Amyloid formation and ER stress markers in vivo To determine whether islet amyloid formation in vivo was associated with alterations in levels of ER stress markers we examined both mouse and human pancreas samples with and without islet amyloid.

Pancreas sections were from human IAPP transgenic mice and non-transgenic controls fed a high-fat diet for 1 year, an intervention associated with islet amyloid formation, decreased beta cell area and secretory dysfunction [30]. Insulin and thioflavin S staining demonstrate the expected amyloid deposition and decreased beta cell area in human IAPP transgenic mice compared with nontransgenic mice (Fig. 5a, e). Immunostaining for BIP and
Table 2 Morphometric analyses of human IAPP transgenic islets cultured for $1,3,5$ and 7 days in $16.7 \mathrm{mmol} / 1$ glucose

Values are mean \pm SEM ${ }^{*} p<0.05$ vs day 1

\begin{tabular}{lcccr}
\hline Culture day & Day 1 $(n=4)$ & Day 3 $(n=4)$ & Day 5 $(n=4)$ & Day 7 $(n=4)$ \\
\hline Amyloid prevalence (\%) & $3.5 \pm 2.4$ & $55 \pm 19$ & $74 \pm 12^{*}$ & $67 \pm 14^{*}$ \\
Amyloid severity (\%) & $0.003 \pm 0.003$ & $1.5 \pm 1.0$ & $2.2 \pm 0.7^{*}$ & $3.0 \pm 1.2^{*}$ \\
Islet cross sectional area $\left(\mu \mathrm{m}^{2}\right)$ & $10,441 \pm 1,497$ & $8,283 \pm 1,326$ & $11,466 \pm 1,912$ & $9,425 \pm 879$ \\
Beta cell area $\left(\mu \mathrm{m}^{2}\right)$ & $6,463 \pm 1,082$ & $4,652 \pm 1,363$ & $5,249 \pm 500$ & $4,460 \pm 802$ \\
Beta cell area/islet area $(\%)$ & $61.7 \pm 1.5$ & $54.9 \pm 7.7$ & $46.3 \pm 3.4$ & $46.9 \pm 4.1$ \\
\hline
\end{tabular}



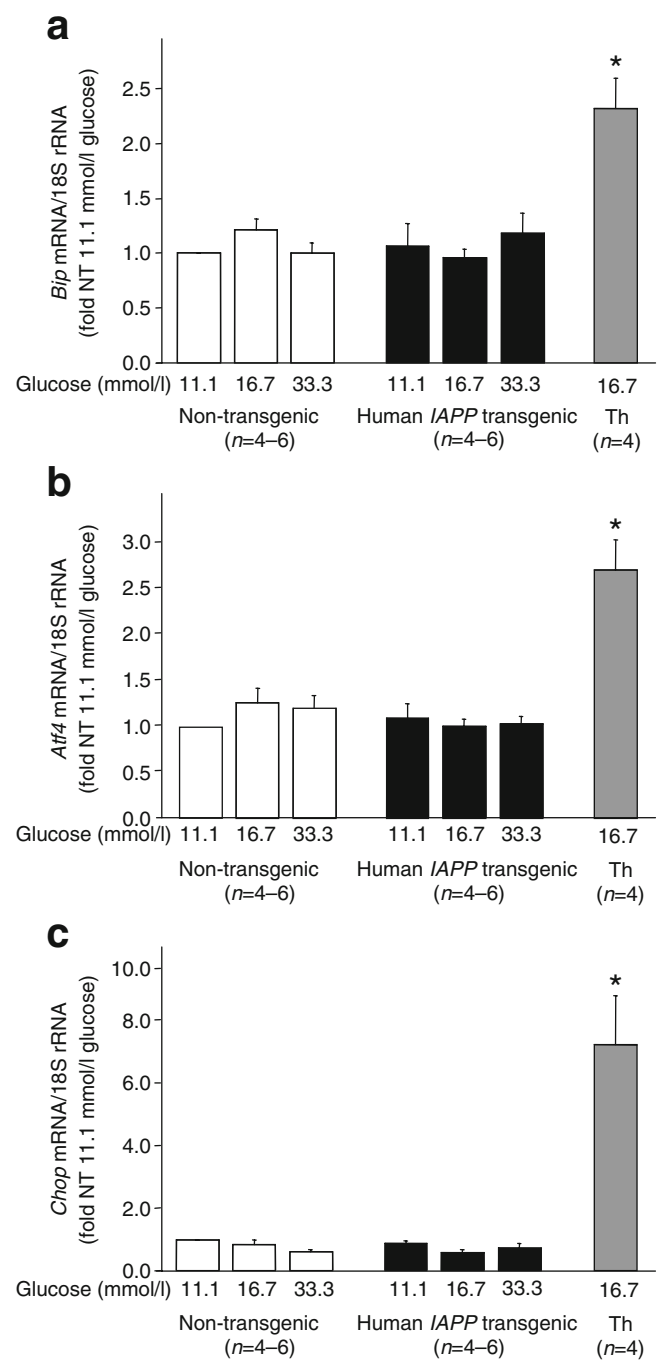

Fig. 1 mRNA levels by real-time PCR for Bip (a), Atf4 (b) and Chop (c), in non-transgenic (white bars) or human IAPP transgenic (black bars) mouse islets cultured for 7 days in $11.1,16.7$ or $33.3 \mathrm{mmol} / \mathrm{l}$ glucose or in non-transgenic islets $16.7 \mathrm{mmol} / 1$ glucose $+0.3 \mu \mathrm{mol} / \mathrm{l}$ thapsigargin (grey bars) for the final $4 \mathrm{~h}$ ( $n=4-6$ per condition). While thapsigargin treatment led to marked increases in mRNA levels of all three ER stress markers, there were no significant differences in Bip, Atf4 or Chop mRNA levels among non-transgenic or human IAPP transgenic islets at any glucose concentration. NT, non-transgenic; Th, thapsigargin. ${ }^{*} p<0.05$ vs non-transgenic islets cultured in $11.1 \mathrm{mmol} / 1$ glucose

XBP1 were both present at similar levels in islets from human IAPP transgenic and non-transgenic mice (Fig. 5b, $\mathrm{c}, \mathrm{f}, \mathrm{g})$. The staining pattern for BIP in mouse pancreas was similar with both antisera (610979 or SPA-826). CHOP staining was not seen in either genotype (Fig. $5 \mathrm{~d}$, h); neither antiserum (sc-575 or ab11419) showed positive staining. Note that faint nuclear staining (antibody ab11419) was present in non-transgenic mice, but this was present in all islet cells and in some exocrine cells, suggesting that it was probably non-specific.

Immunostaining for the same ER stress markers was then performed in human autopsy pancreas sections. These samples were from one non-diabetic control participant with no amyloid deposition (Fig. 5i) and two individuals with type 2 diabetes who differed with respect to islet amyloid deposition (no amyloid in one case, Fig. 5m, and $10 \%$ amyloid severity in the other, Fig. $5 \mathrm{q}$ ). BIP immunoreactivity (using SPA-826) was faintly visible in control islets (Fig. 5j) and was increased in islets from individuals with diabetes, regardless of the presence of amyloid (Fig. 5n, r). No BIP immunoreactivity was seen using 610979 (data not shown). XBP1 staining was not readily detectable in human pancreases with or without diabetes (Fig. 5k, o, s). In contrast, CHOP immunostaining (using ab11419) was present in islets from individuals with diabetes (Fig. 5p, t), but not control islets (Fig. 51). No CHOP immunostaining was seen using sc-575 (not shown). CHOP staining did not differ between participants with diabetes, whether they had amyloid deposition or not, and staining was localised to the cytoplasm rather than the nucleus.

\section{Discussion}

We have demonstrated that the ER stress response is not induced during amyloid deposition in cultured transgenic mouse islets with physiological levels of human IAPP. Culture of human IAPP transgenic islets for 7 days in increasing glucose concentrations resulted in a dosedependent increase in islet amyloid deposition [11], but

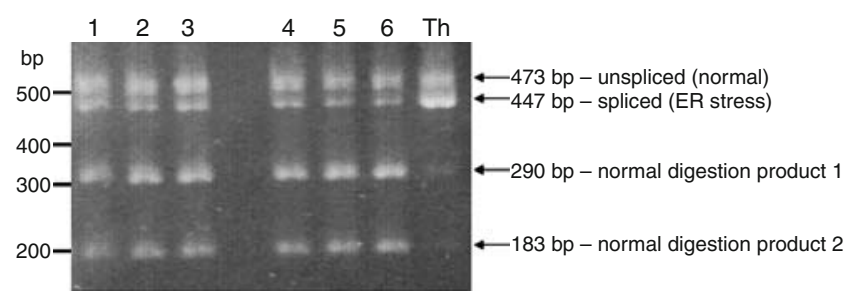

Fig. 2 Xbpl mRNA splicing products analysed by agarose gel electrophoresis in non-transgenic (lanes 1-3) or human IAPP transgenic mouse islets (lanes 4-6) cultured for 7 days in 11.1 (lanes 1 and 4), 16.7 (lanes 2 and 5) or $33.3 \mathrm{mmol} / 1$ glucose (lanes 3 and 6) or non-transgenic islets cultured for 7 days in $16.7 \mathrm{mmol} / 1$ glucose + $0.3 \mu \mathrm{mol} / \mathrm{l}$ thapsigargin for the final $4 \mathrm{~h}(\mathrm{Th})$. The four bands on the gel are the PCR products from intact (473 bp) normally spliced Xbpl mRNA and its two digestion products produced from PstI restriction digestion (product 1 at $290 \mathrm{bp}$ and product 2 at $183 \mathrm{bp}$ ) and the alternatively spliced form of Xbpl mRNA (447 bp). While thapsigargin treatment led to almost complete generation of the alternatively spliced $X b p 1 \mathrm{mRNA}$, there were no differences in the proportion of the four bands in any of the experimental conditions, suggesting that there were no differences in $X b p 1$ mRNA splicing among nontransgenic or human IAPP transgenic islets at any glucose concentration 

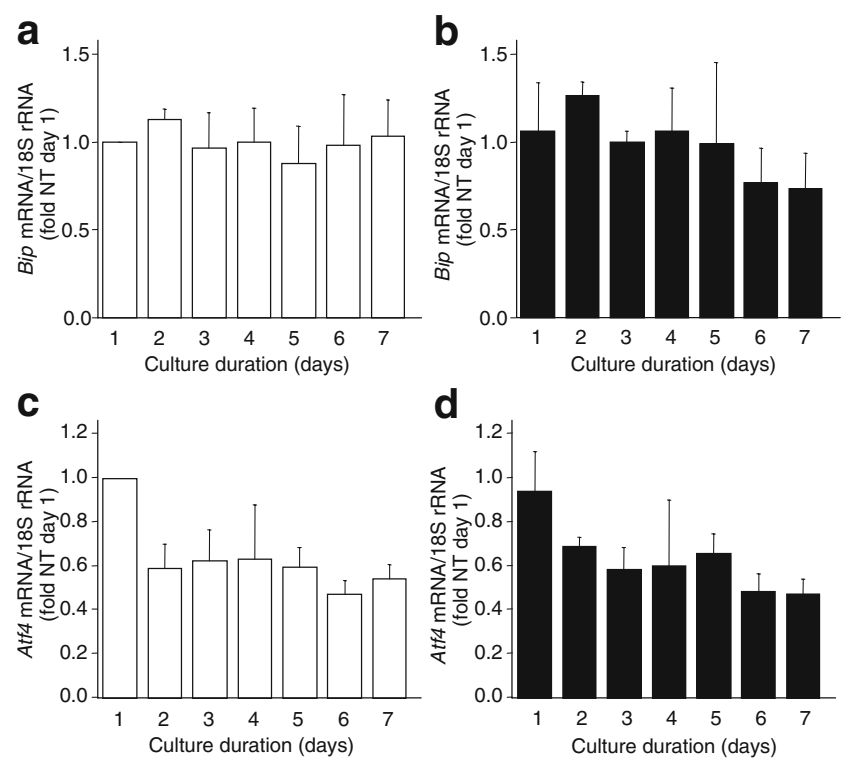

d
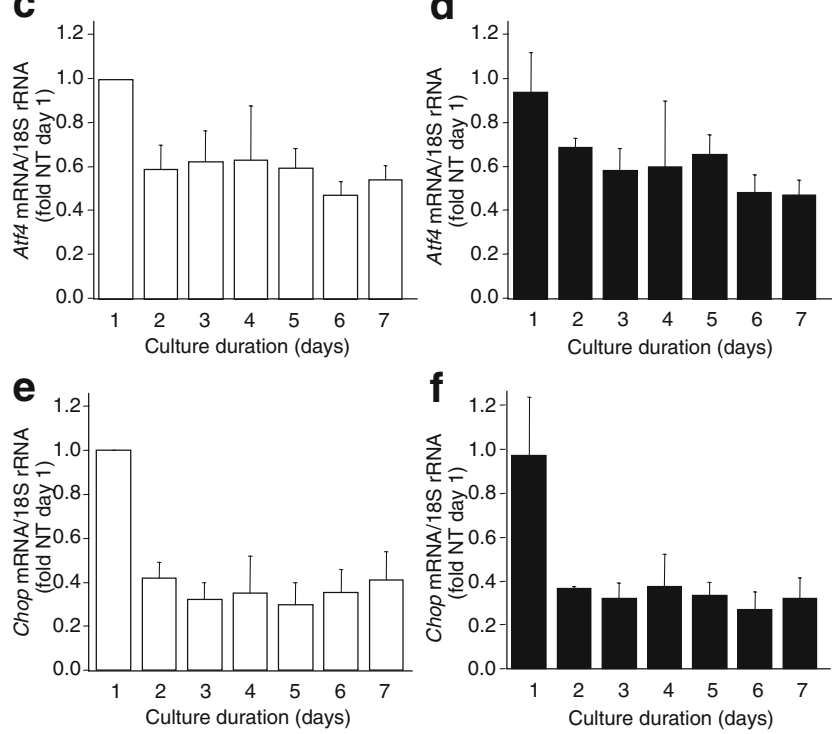

Fig. 3 mRNA levels by real-time PCR for Bip (a, b), Atf4 (c, d) and Chop $(\mathbf{e}, \mathbf{f})$, in non-transgenic (white bars; a, c, e) or human IAPP transgenic mouse islets (black bars; b, d, f) cultured for up to 7 days in $16.7 \mathrm{mmol} / 1$ glucose. Atf 4 and Chop mRNA levels decreased between day 1 and day 2 in both genotypes, but there were no significant differences in Bip, Atf4 or Chop mRNA levels between non-transgenic or human IAPP transgenic islets at any time point ( $n=3$ per condition). NT, non-transgenic

no change in Bip, Atf4 or Chop mRNA levels, nor in changes in splicing of Xbpl mRNA. To rule out the possibility that induction of the ER stress response may have been transitory and that changes were not detectable after 7 days of culture, we also analysed ER stress markers every $24 \mathrm{~h}$ during 7 days of culture in $16.7 \mathrm{mmol} / \mathrm{l}$ glucose. We observed a time-dependent increase in islet amyloid formation [11], but no increases in ER stress markers were observed. In fact, Atf4 and Chop mRNA levels were higher at day 1 than for the remainder of the study, suggesting some residual stress response following islet isolation. However, the increased Atf4 and Chop mRNA levels occurred early in the culture period and were equivalent in human IAPP transgenic and non-transgenic islets, making it unlikely that these changes were associated with islet amyloid deposition. We confirmed our findings in cultured islets by immunostaining pancreas sections where amyloid deposition had occurred in vivo. While we

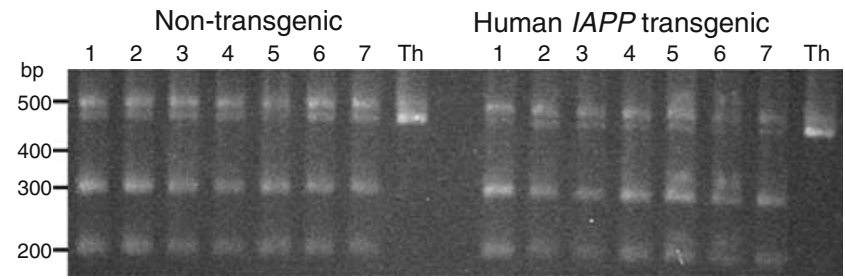

Fig. $4 \mathrm{Xbpl}$ mRNA splicing products analysed by agarose gel electrophoresis as described in Fig. 2 in non-transgenic or human $I A P P$ transgenic mouse islets (lanes $1-7$; days $1-7$ respectively) cultured for up to 7 days in $16.7 \mathrm{mmol} / 1$ glucose or in $16.7 \mathrm{mmol} / 1$ glucose $+0.3 \mu \mathrm{M}$ thapsigargin for the final $4 \mathrm{~h}$ (Th). While thapsigargin treatment led to almost complete generation of the alternatively spliced $X b p 1$ mRNA, there were no differences in $X b p 1$ mRNA splicing between non-transgenic or human IAPP transgenic islets at any time point

detected BIP and XBP1 immunostaining in mouse pancreas following high-fat feeding, and BIP and CHOP immunostaining in human pancreas from participants with diabetes, the staining intensity did not differ regardless of whether amyloid was present or absent. Thus, while certain ER stress markers are upregulated in mice fed a high-fat diet and humans with type 2 diabetes, this does not appear to be related to the presence of amyloid. Taken together, our findings suggest that ER stress is not an obligatory pathway by which islet amyloid results in loss of beta cells. Our data are in line with a recent study showing that beta cell death in response to other toxic stimuli, such as cytokine treatment, can also occur independently of ER stress [31].

Culture of islets in increased glucose for 7 days was not associated with an ER stress response in either human IAPP transgenic or non-transgenic islets. This is in line with two studies demonstrating that elevated non-esterified fatty acids but not increased glucose induced ER stress in insulinoma cell lines, primary beta cells, $d b / d b$ mouse islets and human islets [20,32]. However, it is in contrast to other studies that have demonstrated an effect of glucose concentrations of up to $30 \mathrm{mmol} / \mathrm{l}$ glucose to induce ER stress in rat islets [33] and in human islets from participants with type 2 diabetes, but not normal controls following culture for $24 \mathrm{~h}$ in $11.1 \mathrm{mmol} / \mathrm{l}$ glucose [23]. This highlights the marked differences that can occur in islets or cell lines from different strains or species. An effect of glucose to increase some ER stress markers over 1 to $8 \mathrm{~h}$ has been described [33, 34]. As amyloid deposition occurs over days rather than hours, we did not investigate this acute response in the present study, but we cannot rule out the possibility that glucose induced ER stress over the short term. However the fact that from $24 \mathrm{~h}$ onwards we observed no effect of elevated glucose in non-transgenic islets to upregulate ER stress markers allowed us to distinguish any effect human of IAPP expression and/or amyloid formation from that of glucose alone. 


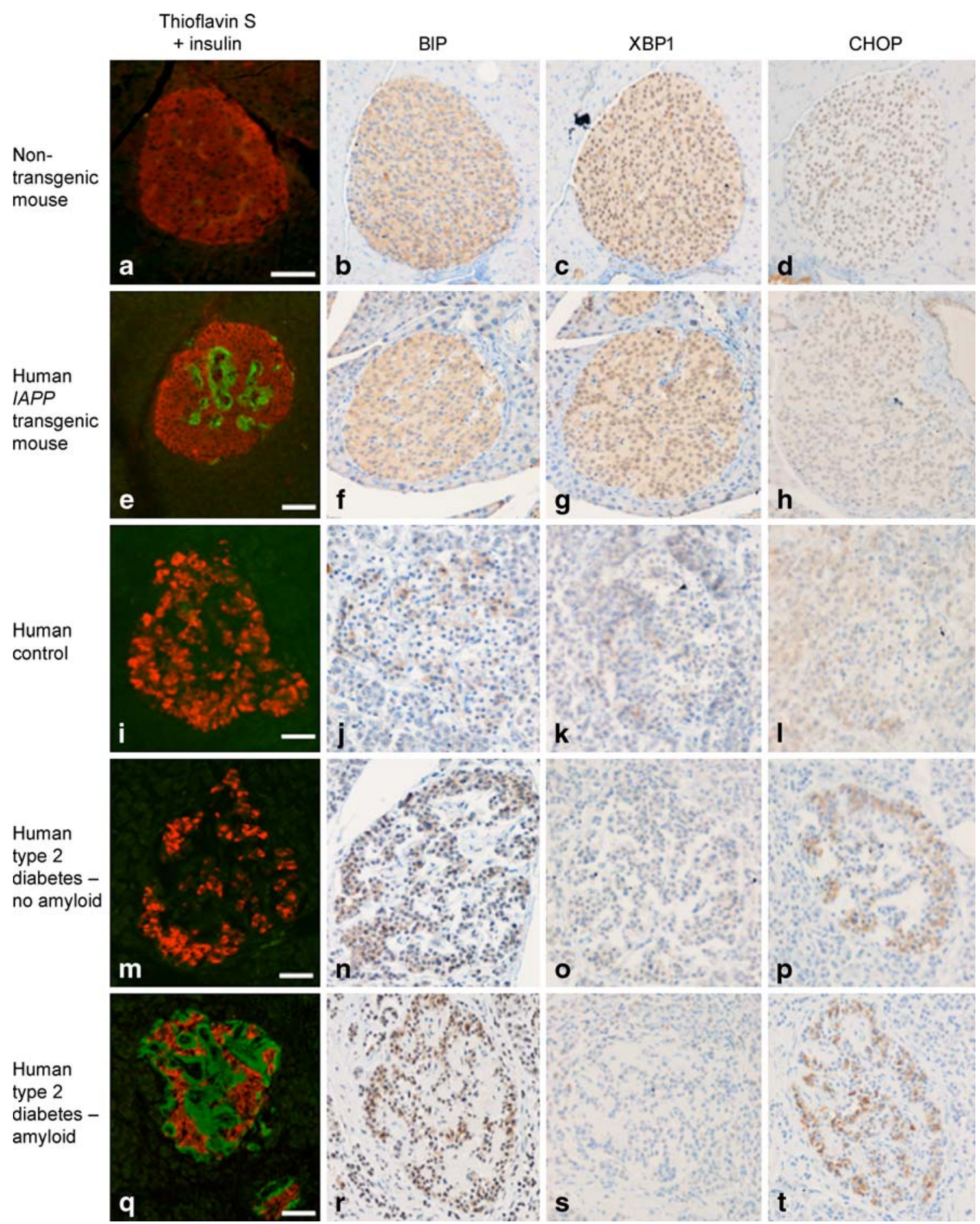

Fig. 5 Pancreas sections from high-fat-fed non-transgenic (a-d) and human IAPP transgenic (e-h) mice and from human participants without diabetes $(\mathbf{i}-\mathbf{l})$, with type 2 diabetes but without amyloid deposition $(\mathbf{m}-\mathbf{p})$, and with type 2 diabetes and significant amyloid deposition $(\mathbf{q}-\mathbf{t})$. Pancreas sections were stained for insulin + thioflavin S (a, e, i, m, q), BIP (b, f, j, n, r), XBP1 (c, g, k, o, s) or CHOP $(\mathbf{d}, \mathbf{h}, \mathbf{l}, \mathbf{p}, \mathbf{t})$. Amyloid deposition and decreased beta cell area were evident in amyloid-containing pancreases from the human IAPP transgenic mouse and the human participant with type 2 diabetes (e, q). BIP and XBP1 immunostaining were present to an equivalent degree in islets from both non-transgenic and human IAPP transgenic mice, whereas CHOP immunostaining was not observed in mouse pancreas. Note that the faint nuclear staining in non-transgenic mouse pancreas (d) is deemed to be non-specific staining as it is present to a similar degree throughout the islet and exocrine pancreas. XBP1 staining was absent from human islets, whereas cytoplasmic staining for BIP and CHOP was present in islets from participants with type 2 diabetes, regardless of the presence of amyloid. Scale bar, $50 \mu \mathrm{m}$ 
In contrast to the lack of effect of high glucose, culture of human IAPP transgenic and non-transgenic islets for 7 days in low $(5.5 \mathrm{mmol} / \mathrm{l})$ glucose was associated with increased Chop mRNA. This resembled a low glucoseinduced integrated stress response [33], rather than a classic ER stress response. These data, together with the fact that culture of human IAPP transgenic islets for 7 days in either 5.5 or $11.1 \mathrm{mmol} / \mathrm{l}$ glucose is only associated with minimal amyloid deposition [11], justified the use of $11.1 \mathrm{mmol} / 1$ glucose as the control condition in this study. In addition, this highlights the caution needed when interpreting changes in markers of stress signalling in isolation. Measuring only CHOP, which can be induced by several stressors [21, 35], rather than all three pathways of the ER stress response (IRE1, ATF6 and PERK) [16, 17], identifies that cells are under stress but gives limited insight into which specific stress response(s) is activated.

Consistent with in vitro studies showing an effect of non-esterified fatty acids to induce beta cell ER stress [20, 32], we demonstrated BIP and XBP1 immunostaining in mouse pancreas samples from animals fed a high-fat diet for 1 year. Further, in line with our in vitro observations, amyloid formation in vivo in human IAPP transgenic highfat-fed mice was not associated with a further increase in BIP or XBP1 immunostaining over that associated with high-fat feeding alone in non-transgenic mice. Interestingly, we did not observe CHOP immunostaining in mouse pancreas, despite the use of two different anti-CHOP antisera (AB11419 and two different lots of sc-575) that have both previously been reported to produce positive staining under conditions of ER stress in the beta cell [20, 36]. This leads us to conclude that in human IAPP transgenic mice, amyloid-induced beta cell loss is not associated with marked increases in the ER stress response.

Elevated ER stress markers have been reported in other models of human IAPP overproduction and amyloid formation. Increased CHOP immunostaining has been reported in association with human IAPP-induced cell death in INS-1 cells overproducing human IAPP and increased caspase 12 immunostaining in human IAPPtransgenic rat pancreas [22]; in addition other elements of the ER stress pathway were also upregulated in transgenic islets overexpressing human IAPP and not in islets overexpressing non-amyloidogenic rodent Iapp to the same degree [27]. While the levels of human IAPP were not quantified in this model, examination of the western blots demonstrates that the overproduction is marked [27]. Another study reported that extracellular treatment of MIN6 cells or cultured human islets with human IAPP resulted in induction of ER stress and cell death [26]. While these studies provide compelling evidence for a role of human IAPP in the ER stress response, it is important to note that both studies used production or treatment of human IAPP at levels that are significantly higher than is normally seen. In normal humans the circulating levels of human IAPP are approximately $2 \%$ of insulin levels [37] and, in fact, levels of human IAPP in human diabetes are decreased rather than increased $[38,39]$. Our human IAPP transgenic mice produce human IAPP at a 1:1 ratio with endogenous mouse IAPP, and at a 2:100 level with insulin [30] providing a model of islet amyloid formation more akin to the physiological levels of human IAPP relative to insulin. Thus, our findings suggest that islet amyloid formation that occurs at physiological levels of human IAPP may not result in ER stress, but that marked increases in amyloidogenic human IAPP may result in an ER stress response.

Of note, the process of human IAPP aggregation is quite likely to be different from the misfolding of other welldescribed proteins that elicit a strong ER stress response. Mutations in the insulin 2 gene that disrupt disulfide bond formation result in proinsulin misfolding and marked ER stress, leading ultimately to beta cell apoptosis and diabetes $[40,41]$. Other examples include mutations in the cystic fibrosis transmembrane receptor or alpha-1 antitrypsin, which again cause the proteins to become inherently misfolded and retained within the ER $[42,43]$. In contrast, the soluble and aggregated forms of human IAPP do not differ in their amino-acid sequence, and while human IAPP can be aggressively amyloidogenic in vitro, under normal conditions human IAPP is properly folded and secreted from the beta cell. Thus, human IAPP does not have an inherent tendency to induce ER stress, but can become aggregated under certain conditions. Our data support the concept that this aggregation is not associated with activation of an ER stress response.

The data regarding ER stress markers in type 2 diabetes, where amyloid is known to occur, have been somewhat mixed. Several ER stress markers were shown to be elevated in pancreas from individuals with type 2 diabetes in one study [20], with only modest increases reported in another [23]. A third study suggested that ER stress markers are increased in type 2 diabetes; however, only CHOP was measured, making it difficult to conclude that the pathway induced was in fact ER stress [22]. We found that both BIP and CHOP immunoreactivity is increased in islets from participants with type 2 diabetes compared with non-diabetic control islets. However, importantly the CHOP staining we observed was cytoplasmic, not nuclear; the latter would be required to indicate increased $\mathrm{CHOP}$ activity in beta cells. Further, our findings demonstrate that the presence of BIP and CHOP immunoreactivity in human type 2 diabetes is unrelated to the presence of islet amyloid, as BIP and CHOP staining were both present in islets from individuals with diabetes whether or not amyloid was present. Many abnormalities exist in islets from individuals 
with type 2 diabetes, and it is therefore also not possible to ascribe the presence of an ER stress response in autopsy pancreas sections from type 2 diabetes to amyloid or any other single abnormality. It is likely, in fact, that any increase in ER stress markers in this disease state arise because of a combination of factors resulting in accumulation of unfolded or misfolded proteins in the ER.

In summary, we have shown that islet amyloid formation, both in vitro and in vivo, is not associated with induction of the ER stress response, and that while human IAPP production or aggregation may be associated with ER stress under certain conditions, it does not appear to be an obligatory mediator of the toxic effects of islet amyloid deposition.

Acknowledgements We thank R. Bhatti, B. Barrow, M. Watts, M. Peters, J. Willard and C. Braddock for excellent technical support and D. R. Laybutt for provision of CHOP antibody. This work was supported by the Department of Veterans Affairs, VA Puget Sound Health Care System (Seattle, WA, USA), National Institutes of Health grants DK17047, DK74404, DK75998 and DK07247 and the American Diabetes Association. S. Zraika and J. Udayasankar are supported by Juvenile Diabetes Research Foundation Postdoctoral Fellowship Awards.

Duality of interest The authors declare that there is no duality of interest associated with this manuscript.

\section{References}

1. Westermark P (1972) Quantitative studies on amyloid in the islets of Langerhans. Ups J Med Sci 77:91-94

2. Clark A, Wells CA, Buley ID et al (1988) Islet amyloid, increased A-cells, reduced B cells and exocrine fibrosis - quantitative changes in the pancreas in type-2 diabetes. Diab Res Clin Exptl 9:151-159

3. Lorenzo A, Razzaboni B, Weir GC, Yankner BA (1994) Pancreatic islet cell toxicity of amylin associated with type 2 diabetes mellitus. Nature 368:756-760

4. Mirzabekov TA, Lin MC, Kagan BL (1996) Pore formation by the cytotoxic islet amyloid peptide amylin. J Biol Chem 271:1988-1992

5. Janson J, Ashley RH, Harrison D, McIntyre S, Butler PC (1999) The mechanism of islet amyloid polypeptide toxicity is membrane disruption by intermediate-sized toxic amyloid particles. Diabetes 48:491-498

6. Bai JZ, Saafi EL, Zhang S, Cooper GJ (1999) Role of $\mathrm{Ca}^{2+}$ in apoptosis evoked by human amylin in pancreatic islet beta-cells. Biochem J 343:53-61

7. Saafi EL, Konarkowska B, Zhang S, Kistler J, Cooper GJ (2001) Ultrastructural evidence that apoptosis is the mechanism by which human amylin evokes death in RINm5F pancreatic islet beta-cells. Cell Biol Int 25:339-350

8. Westermark P, Engström U, Johnson KH, Westermark GT, Betsholtz C (1990) Islet amyloid polypeptide-pinpointing amino acid residues linked to amyloid fibril formation. Proc Natl Acad Sci USA 87:5036-5040

9. Butler AE, Janson J, Soeller WC, Butler PC (2003) Increased beta-cell apoptosis prevents adaptive increase in beta-cell mass in mouse model of type 2 diabetes: evidence for role of islet amyloid formation rather than direct action of amyloid. Diabetes 52:2304 2314
10. Hull RL, Westermark GT, Westermark P, Kahn SE (2004) Islet amyloid: a critical entity in the pathogenesis of type 2 diabetes. J Clin Endocrinol Metab 89:3629-3643

11. Zraika S, Hull RL, Udayasankar J et al (2007) Glucose- and timedependence of islet amyloid formation in vitro. Biochem Biophys Res Commun 354:234-239

12. Zraika S, Hull RL, Udayasankar J et al (2009) Oxidative stress is induced by islet amyloid formation and time-dependently mediates amyloid-induced beta cell apoptosis. Diabetologia 52:626-635

13. Betsholtz C, Svensson V, Rorsman F et al (1989) Islet amyloid polypeptide (IAPP): cDNA cloning and identification of an amyloidogenic region associated with the species-specific occurrence of age-related diabetes-mellitus. Exp Cell Res 183:484-493

14. Ohnishi S, Takano K (2004) Amyloid fibrils from the viewpoint of protein folding. Cell Mol Life Sci 61:511-524

15. Horwich A (2002) Protein aggregation in disease: a role for folding intermediates forming specific multimeric interactions. J Clin Invest 110:1221-1232

16. Mori K (2000) Tripartite management of unfolded proteins in the endoplasmic reticulum. Cell 101:451-454

17. Kaufman RJ (2002) Orchestrating the unfolded protein response in health and disease. J Clin Invest 110:1389-1398

18. Oyadomari S, Takeda K, Takiguchi M et al (2001) Nitric oxideinduced apoptosis in pancreatic beta cells is mediated by the endoplasmic reticulum stress pathway. Proc Natl Acad Sci USA 98:10845-10850

19. Kharroubi I, Ladriere L, Cardozo AK, Dogusan Z, Cnop M, Eizirik DL (2004) Free fatty acids and cytokines induce pancreatic beta-cell apoptosis by different mechanisms: role of nuclear factor-kappaB and endoplasmic reticulum stress. Endocrinology 145:5087-5096

20. Laybutt DR, Preston AM, Akerfeldt MC et al (2007) Endoplasmic reticulum stress contributes to beta cell apoptosis in type 2 diabetes. Diabetologia 50:752-763

21. Oyadomari S, Mori M (2004) Roles of CHOP/GADD153 in endoplasmic reticulum stress. Cell Death Differ 11:381-389

22. Huang CJ, Lin CY, Haataja L et al (2007) High expression rates of human islet amyloid polypeptide induce endoplasmic reticulum stress mediated beta-cell apoptosis, a characteristic of humans with type 2 but not type 1 diabetes. Diabetes 56:2016-2027

23. Marchetti P, Bugliani M, Lupi R et al (2007) The endoplasmic reticulum in pancreatic beta cells of type 2 diabetes patients. Diabetologia 50:2486-2494

24. Nakagawa T, Zhu H, Morishima N et al (2000) Caspase-12 mediates endoplasmic-reticulum-specific apoptosis and cytotoxicity by amyloid-beta. Nature 403:98-103

25. Hetz C, Russelakis-Carneiro M, Maundrell K, Castilla J, Soto C (2003) Caspase-12 and endoplasmic reticulum stress mediate neurotoxicity of pathological prion protein. Embo J 22:54355445

26. Casas S, Gomis R, Gribble FM, Altirriba J, Knuutila S, Novials A (2007) Impairment of the ubiquitin-proteasome pathway is a downstream endoplasmic reticulum stress response induced by extracellular human islet amyloid polypeptide and contributes to pancreatic beta-cell apoptosis. Diabetes 56:2284-2294

27. Huang CJ, Haataja L, Gurlo T et al (2007) Induction of endoplasmic reticulum stress-induced beta-cell apoptosis and accumulation of polyubiquitinated proteins by human islet amyloid polypeptide. Am J Physiol Endocrinol Metab 293:E1656-E1662

28. Hull RL, Shen Z, Watts MR et al (2005) Long term treatment with rosiglitazone and metformin reduce the extent of, but do not prevent, islet amyloid deposition in mice expressing the gene for human islet amyloid polypeptide. Diabetes 54:2235-2244

29. Zraika S, Hull RL, Udayasankar J et al (2007) Identification of the amyloid-degrading enzyme neprilysin in mouse islets and potential role in islet amyloidogenesis. Diabetes 56:304-310 
30. Hull RL, Andrikopoulos S, Verchere CB et al (2003) Increased dietary fat promotes islet amyloid formation and $\beta$-cell secretory dysfunction in a transgenic mouse model of islet amyloid. Diabetes 52:372-379

31. Åkerfeldt MC, Howes J, Chan JY et al (2008) Cytokine-induced $\beta$-cell death is independent of endoplasmic reticulum stress signaling. Diabetes 57:3034-3044

32. Cunha DA, Hekerman P, Ladriere L et al (2008) Initiation and execution of lipotoxic ER stress in pancreatic beta-cells. J Cell Sci 121:2308-2318

33. Elouil H, Bensellam M, Guiot Y et al (2007) Acute nutrient regulation of the unfolded protein response and integrated stress response in cultured rat pancreatic islets. Diabetologia 50:14421452

34. Lipson KL, Fonseca SG, Ishigaki S et al (2006) Regulation of insulin biosynthesis in pancreatic beta cells by an endoplasmic reticulum-resident protein kinase IRE1. Cell Metab 4:245-254

35. Eizirik DL, Bjorklund A, Cagliero E (1993) Genotoxic agents increase expression of growth arrest and DNA damage-inducible genes gadd 153 and gadd 45 in rat pancreatic islets. Diabetes 42:738-745

36. Haataja L, Gurlo T, Huang CJ, Butler PC (2008) Many commercially available antibodies for detection of CHOP expression as a marker of endoplasmic reticulum stress fail specificity evaluation. Cell Biochem Biophys 51:105-107
37. Knowles NG, Landchild MA, Fujimoto WY, Kahn SE (2002) Insulin and amylin release are both diminished in first-degree relatives of subjects with type 2 diabetes. Diabetes Care 25:292297

38. Butler PC, Chou J, Carter WB et al (1990) Effects of meal ingestion on plasma amylin concentration in NIDDM and nondiabetic humans. Diabetes 39:752-756

39. Kahn SE, Verchere CB, Andrikopoulos S et al (1998) Reduced amylin release is a characteristic of impaired glucose tolerance and type 2 diabetes in Japanese Americans. Diabetes 47:640645

40. Yoshioka M, Kayo T, Ikeda T, Koizumi A (1997) A novel locus, Mody4, distal to D7Mit189 on chromosome 7 determines earlyonset NIDDM in nonobese C57BL/6 (Akita) mutant mice. Diabetes 46:887-894

41. Herbach N, Rathkolb B, Kemter E et al (2007) Dominant-negative effects of a novel mutated Ins2 allele causes early-onset diabetes and severe beta-cell loss in Munich Ins2C95S mutant mice. Diabetes 56:1268-1276

42. Riordan JR (1999) Cystic fibrosis as a disease of misprocessing of the cystic fibrosis transmembrane conductance regulator glycoprotein. Am J Hum Genet 64:1499-1504

43. Teckman JH, Qu D, Perlmutter DH (1996) Molecular pathogenesis of liver disease in alpha1-antitrypsin deficiency. Hepatology 24:1504-1516 